\title{
Association of chest pain versus dyspnea as presenting symptom for coronary angiography with demographics, coronary anatomy, and 2-year mortality
}

Rajiv Paudel ${ }^{1}$, Natalia Beridze ${ }^{1}$, Wilbert S. Aronow ${ }^{1}$, Chul Ahn², Abdallah Sanaani ${ }^{1}$, Pallak Agarwal ${ }^{1}$, Kim Farell ${ }^{1}$, Diwakar Jain ${ }^{1}$, Robert Timmermans ${ }^{1}$, Howard A. Cooper ${ }^{1}$, Julio A Panza ${ }^{1}$

\begin{abstract}
${ }^{1}$ Cardiology Division, Department of Medicine, Westchester Medical Center, New York Medical College, Valhalla, NY, USA

${ }^{2}$ Department of Clinical Sciences, University of Texas Southwestern Medical Center, Dallas, TX, USA
\end{abstract}

Submitted: 24 January 2015

Accepted: 4 February 2015

Arch Med Sci 2016; 12, 4: 742-746

DOI: 10.5114/aoms.2016.60959

Copyright $\odot 2016$ Termedia \& Banach

\section{Abstract}

Introduction: The association of chest pain versus dyspnea with demographics, coronary angiographic findings, and outcomes of patients undergoing coronary angiography is unknown.

Material and methods: We studied 1,053 patients who had coronary angiography to investigate the association of chest pain versus dyspnea with demographics, coronary angiographic findings, and outcomes.

Results: Of 1,053 patients, 654 (62\%) had chest pain, 229 (22\%) had dyspnea, and $117(11 \%)$ had chest pain and dyspnea. Patients with dyspnea were older $(p<0.0001)$ and had higher serum creatinine $(p=0.0011)$, lower left ventricular ejection fraction (LVEF) $(p<0.0001)$, more cardiogenic shock $(p=0.0004)$, less obstructive coronary artery disease (CAD) $(p<0.0001)$, less percutaneous coronary intervention $(p<0.0001)$, and similar 2 -year mortality. Stepwise Cox regression analysis showed no significant difference in mortality between chest pain and dyspnea. Significant risk factors for time to death were age (hazard ratio $(H R)=1.07, p<0.0001$ ), serum creatinine $(H R=1.5, p<0.0001)$, body mass index $(H R=0.93, p=0.005)$, and obstructive CAD graft $(\mathrm{HR}=3.2, p=0.011)$.

Conclusions: Patients undergoing coronary angiography presenting with dyspnea were older and had higher serum creatinine, lower LVEF, more frequent cardiogenic shock, less obstructive $C A D$, and less percutaneous coronary intervention compared to patients presenting with chest pain but similar 2-year mortality.

Key words: dyspnea, chest pain, coronary angiography.

\section{Introduction}

Chest pain and dyspnea are the most common presenting symptoms of acute or stable coronary artery disease (CAD). Exertional angina pectoris caused by myocardial ischemia is a common manifestation of CAD. However, myocardial ischemia may also be manifested as dyspnea rather than chest tightness and is referred to as an angina equivalent [1, 2]. Usually this type of dyspnea is exertional and is thought to be related to a transient rise in left ventricular end-diastolic pressure caused by myocardial ischemia superimposed on reduced left ventricular compli-

\section{Corresponding author:} Wilbert S. Aronow MD, FACC, FAHA

Cardiology Division New York Medical College Macy Pavilion, Room 138 Valhalla, NY 10595, USA Phone: 914-493-5311 Fax: 914-235-6274

E-mail:wsaronow@aol.com 
ance [1]. Not infrequently the dyspnea will occur in combination with angina pectoris [1].

To the best of our knowledge, the association of chest pain, dyspnea, and chest pain plus dyspnea as the presenting symptom for patients undergoing coronary angiography with patients' demographics, coronary anatomy, and clinical outcomes has not been previously reported. We hypothesized that the clinical presentation leading to the indication for coronary angiography in patients with known or suspected CAD is associated with certain baseline clinical characteristics and impacts on prognosis. Hence, the present study investigated the association of chest pain versus dyspnea as the presenting symptom for coronary angiography with demographics, coronary anatomy, and 2-year mortality in all patients undergoing coronary angiography at Westchester Medical Center/New York Medical College during 2012 after the performance of coronary angiography.

\section{Material and methods}

We performed a retrospective analysis in all 1,053 patients who underwent coronary angiography during 2012 at Westchester Medical Center/ New York Medical College investigating the association of chest pain, dyspnea, and chest pain plus dyspnea as the presenting symptom for coronary angiography with demographics, coronary anatomy, and 2-year mortality. Patients with ST-segment myocardial infarction, non-ST-segment elevation myocardial infarction, unstable angina pectoris, and stable angina pectoris with an abnormal stress test were included in this study. Patients with an abnormal stress test who were asymptomatic were excluded from this study. Obstructive CAD was defined as greater than $50 \%$ stenosis of a major coronary artery. Nonobstructive CAD was defined as less than $50 \%$ obstruction of a major coronary artery. Obstructive CAD included greater than $50 \%$ obstruction in obstructed grafts as well as in a native major coronary artery. We do not have data on fractional flow reserve. Coronary revascularization was performed only if there was greater than $70 \%$ obstructive disease. Cardiogenic shock was defined as systolic blood pressure less than $80 \mathrm{~mm} \mathrm{Hg}$, a cardiac index less than $1.8 \mathrm{l} / \mathrm{min} / \mathrm{m}^{2}$, and a cardiac index less than $2.0 \mathrm{l} / \mathrm{min} / \mathrm{m}^{2}$ at the time of coronary angiography.

\section{Statistical analysis}

Analysis of variance (ANOVA) tests were conducted to investigate whether there were significant differences in continuous risk factors among these 3 groups. The $\chi^{2}$ or Fisher's exact test was used to examine whether there were significant differences in categorical risk factors, coronary an- giographic findings and clinical outcomes among these 3 groups. Bonferroni corrections were used to account for multiple comparisons. Survival analysis was conducted using 2 groups only: the chest pain only group and the dyspnea only group. The log-rank test was used to determine the difference in time to death between 2 groups. Univariate Cox regression analysis was used to investigate the association between the risk factors and time to death. Stepwise Cox regression analysis was performed to identify significant independent risk factors for time to death. Risk factors with a $p$-value $<0.2$ from univariate Cox regression analyses were entered as candidate variables for stepwise Cox regression analysis. Only risk factors with a $p$-value $<0.2$ were included in the stepwise Cox regression analysis. We obtained mortality data by use of the Social Security Death Index for each patient.

\section{Results}

Of the 1,053 patients, 654 (62\%) had chest pain, 229 (22\%) had dyspnea, 117 (11\%) had chest pain and dyspnea, and 53 (5\%) had an abnormal stress test with no symptoms. Table I shows the baseline characteristics and $p$-values of our patients with chest pain, dyspnea and chest pain plus dyspnea. Table I shows the drugs the patients were taking when they underwent coronary angiography. Table II shows the association of chest pain, dyspnea, and chest pain plus dyspnea with the coronary angiographic findings. Table III shows the association of chest pain, dyspnea, and chest pain plus dyspnea with the incidence of percutaneous coronary intervention, coronary artery bypass grafting, and cardiogenic shock after performance of coronary angiography and 2-year mortality data after coronary angiography. Table IV shows the significant risk factors from stepwise Cox regression analysis for time to death. The log rank test showed no significant difference in time to death between the chest pain group and the dyspnea group.

\section{Discussion}

In 1,443 patients without known CAD undergoing computed tomographic angiography, both dyspnea (odds ratio $(O R)=1.9, p=0.02$ ) and typical angina pectoris $(\mathrm{OR}=1.9, p=0.01)$ were associated with obstructive CAD [3]. In a meta-analysis of 6 studies of 5,753 patients with dyspnea and 24,491 patients with chest pain as the clinical indication for stress testing, there was no difference in the incidence of ischemia between the groups [4]. However, at follow-up, patients with dyspnea had a 2.57 times higher annual mortality rate $(p<0.001)$ [4]. Dyspnea is a common symptom in 
Table I. Baseline characteristics of patients with chest pain, dyspnea, and chest pain plus dyspnea as presenting symptoms for coronary angiography

\begin{tabular}{|c|c|c|c|c|c|c|}
\hline Variable & $\begin{array}{l}\text { Chest pain } \\
(n=654)\end{array}$ & $\begin{array}{l}\text { Dyspnea } \\
(n=229)\end{array}$ & $\begin{array}{l}\text { Chest pain } \\
\text { plus dyspnea } \\
(n=117)\end{array}$ & $\begin{array}{c}P \text {-value } \\
\text { chest pain } \\
\text { vs. dyspnea }\end{array}$ & $\begin{array}{l}P \text {-value } \\
\text { chest pain } \\
\text { vs. both }\end{array}$ & $\begin{array}{l}P \text {-value } \\
\text { dyspnea } \\
\text { vs. both }\end{array}$ \\
\hline Age [years] & $63 \pm 12$ & $67 \pm 12$ & $64 \pm 14$ & $<0.0001$ & NS & 0.03 \\
\hline Men & $418(64 \%)$ & $141(62 \%)$ & $72(62 \%)$ & NS & NS & NS \\
\hline Women & $236(36 \%)$ & $88(38 \%)$ & $45(38 \%)$ & NS & NS & NS \\
\hline Smoking & 355 (54\%) & $130(57 \%)$ & $75(64 \%)$ & NS & NS & NS \\
\hline Hypertension & $465(71 \%)$ & $175(76 \%)$ & $91(78 \%)$ & NS & NS & NS \\
\hline Dyslipidemia & $438(67 \%)$ & $135(59 \%)$ & $69(59 \%)$ & 0.03 & NS & NS \\
\hline Diabetes & $209(32 \%)$ & $88(38 \%)$ & $46(39 \%)$ & NS & NS & NS \\
\hline Body mass index $\left[\mathrm{kg} / \mathrm{m}^{2}\right]$ & $29.2 \pm 6.7$ & $29.9 \pm 7.7$ & $30.8 \pm 6.3$ & NS & NS & NS \\
\hline Serum creatinine $[\mathrm{mg} / \mathrm{dl}]$ & $1.08 \pm 0.95$ & $1.32 \pm 1.05$ & $1.09 \pm 0.80$ & 0.002 & NS & 0.04 \\
\hline LVEF (\%) & $54 \pm 11$ & $47 \pm 16$ & $50 \pm 13$ & $<0.0001$ & 0.01 & 0.04 \\
\hline Coronary artery disease & $596(91 \%)$ & $206(90 \%)$ & $105(90 \%)$ & NS & NS & NS \\
\hline $\begin{array}{l}\text { Peripheral arterial } \\
\text { disease }\end{array}$ & $41(6 \%)$ & $13(6 \%)$ & $6(5 \%)$ & NS & NS & NS \\
\hline Carotid arterial disease & $9(1 \%)$ & $6(3 \%)$ & $0(0 \%)$ & NS & NS & NS \\
\hline Prior $\mathrm{PCl}$ & 159 (24\%) & $39(17 \%)$ & $32(27 \%)$ & 0.03 & NS & 0.03 \\
\hline Prior CABG & $73(11 \%)$ & $23(10 \%)$ & $20(17 \%)$ & NS & NS & NS \\
\hline Abnormal stress test & $228(78 \%)$ & $70(75 \%)$ & $30(77 \%)$ & NS & NS & NS \\
\hline Aspirin & 453 (94\%) & $133(86 \%)$ & $82(96 \%)$ & 0.002 & NS & 0.02 \\
\hline Clopidogrel & $270(56 \%)$ & $44(29 \%)$ & $48(57 \%)$ & $<0.0001$ & NS & $<0.0001$ \\
\hline$\beta$-Blockers & $386(83 \%)$ & $127(85 \%)$ & $69(83 \%)$ & NS & NS & NS \\
\hline ACEI & $270(59 \%)$ & $86(58 \%)$ & $48(58 \%)$ & NS & NS & NS \\
\hline Statins & $410(89 \%)$ & $113(75 \%)$ & 69 (83\%) & $<0.0001$ & NS & NS \\
\hline
\end{tabular}

$L V E F$ - left ventricular ejection fraction, $P C l$ - percutaneous coronary intervention, CABG - coronary artery bypass grafting.

German chest pain units, with the 3-month mortality being 4 times higher than in patients without dyspnea $(p<0.05)$ [5].

In 10,870 patients referred for symptom-limited exercise testing, typical angina pectoris was associated with an increased risk of mortality compared with nonanginal chest pain (hazard ratio $(\mathrm{HR})=2.7, p=0.002$ ) but not with atypical angina pectoris [6]. Patients with nonobstructive CAD have a higher risk of mortality than patients with normal coronary angiograms [7]. At 5-year follow up, all-cause mortality occurred in 41 of 602 (7\%) patients with normal coronary angiograms versus 80 of 695 (12\%) patients with nonobstructive CAD ( $p=0.004$ by log-rank test) [7]. Coronary artery lesions require physiological assessment [8]. Control of blood pressure and serum low-density lipoprotein cholesterol may reduce progression of CAD [9].

To the best of our knowledge, the association of chest pain versus dyspnea as the presenting symptom for coronary angiography with demographics, coronary anatomy, and clinical outcomes has not been previously reported. The present study shows that in our 1,053 patients undergoing coronary angiography, the presenting symptoms for performance of coronary angiography were chest pain in $62 \%$, dyspnea in $22 \%$, chest pain plus dyspnea in $11 \%$, and an abnormal stress test without symptoms in $5 \%$ of our patients. Compared to patients who presented with chest pain, patients who presented with dyspnea were older (67 years vs. 63 years, $p<0.0001$ ), had higher serum creatinine $(1.3 \mathrm{mg} / \mathrm{dl}$ vs. $1.1 \mathrm{mg} / \mathrm{dl}$, $p=0.002$ ), had a lower left ventricular ejection fraction (47\% vs. 54\%, $p<0.0001$ ), had higher prevalence of cardiogenic shock (5\% vs. $1 \%$, $p=0.0004)$, had less obstructive CAD (45\% vs. $63 \%$, $p=0.0004)$, had more nonobstructive CAD (45\% vs. $28 \%, p<0.0001)$, had less percutaneous coronary intervention ( $10 \%$ vs. $31 \%, p<0.0001)$, were 
Table II. Association of patients with chest pain, dyspnea, and chest pain plus dyspnea with coronary angiographic findings

\begin{tabular}{|c|c|c|c|c|c|c|}
\hline Variable & $\begin{array}{l}\text { Chest pain } \\
(n=654)\end{array}$ & $\begin{array}{l}\text { Dyspnea } \\
(n=229)\end{array}$ & $\begin{array}{l}\text { Chest pain } \\
\text { plus dyspnea } \\
(n=117)\end{array}$ & $\begin{array}{c}P \text {-value } \\
\text { chest pain } \\
\text { vs. dyspnea }\end{array}$ & $\begin{array}{l}P \text {-value } \\
\text { chest pain } \\
\text { vs. both }\end{array}$ & $\begin{array}{l}P \text {-value } \\
\text { dyspnea } \\
\text { vs. both }\end{array}$ \\
\hline Obstructive CAD & $410(63 \%)$ & $103(45 \%)$ & $76(65 \%)$ & $<0.001$ & NS & 0.0004 \\
\hline Obstructive LM CAD & $26(4 \%)$ & $13(6 \%)$ & $8(7 \%)$ & NS & NS & NS \\
\hline Nonobstructive LM CAD & $148(23 \%)$ & $52(23 \%)$ & $32(27 \%)$ & NS & NS & NS \\
\hline $\begin{array}{l}\text { Obstructive LAD/ } \\
\text { diagonal CAD }\end{array}$ & $263(40 \%)$ & $80(35 \%)$ & $47(40 \%)$ & NS & NS & NS \\
\hline $\begin{array}{l}\text { Nonobstructive LAD/ } \\
\text { diagonal CAD }\end{array}$ & $314(48 \%)$ & $121(53 \%)$ & $52(44 \%)$ & NS & NS & NS \\
\hline $\begin{array}{l}\text { Obstructive LCX/ } \\
\text { marginal CAD }\end{array}$ & $181(28 \%)$ & $46(20 \%)$ & $30(26 \%)$ & NS & NS & NS \\
\hline $\begin{array}{l}\text { Nonobstructive LCX/ } \\
\text { marginal CAD }\end{array}$ & $361(55 \%)$ & $139(61 \%)$ & $61(52 \%)$ & NS & NS & NS \\
\hline Obstructive right CAD & $256(39 \%)$ & $65(28 \%)$ & 47 (40\%) & 0.02 & NS & 0.03 \\
\hline $\begin{array}{l}\text { Nonobstructive right } \\
\text { CAD }\end{array}$ & $304(46 \%)$ & $121(53 \%)$ & $44(38 \%)$ & NS & NS & 0.02 \\
\hline Obstructive grafts & $\begin{array}{l}22 / 70 \\
(31 \%)\end{array}$ & $6 / 23(26 \%)$ & $5 / 17(29 \%)$ & NS & NS & NS \\
\hline Patent grafts & $\begin{array}{l}48 / 70 \\
(69 \%)\end{array}$ & $17 / 23(74 \%)$ & $12 / 17(71 \%)$ & NS & NS & NS \\
\hline
\end{tabular}

$L M$ - left main, CAD - coronary artery disease, $L A D$ - left anterior descending, $L C X$ - left circumflex.

Table III. Association of patients with chest pain, dyspnea, and chest pain plus dyspnea with outcomes

\begin{tabular}{|c|c|c|c|c|c|c|}
\hline Variable & $\begin{array}{l}\text { Chest pain } \\
(n=654)\end{array}$ & $\begin{array}{l}\text { Dyspnea } \\
(n=229)\end{array}$ & $\begin{array}{l}\text { Chest pain } \\
\text { plus dyspnea } \\
(n=117)\end{array}$ & $\begin{array}{c}P \text {-value } \\
\text { chest pain } \\
\text { vs. dyspnea }\end{array}$ & $\begin{array}{c}P \text {-value } \\
\text { chest pain } \\
\text { vs. both }\end{array}$ & $\begin{array}{l}P \text {-value } \\
\text { dyspnea } \\
\text { vs. both }\end{array}$ \\
\hline $\mathrm{PCl}$ & $205(31 \%)$ & $24(10 \%)$ & 39 (33\%) & $<0.0001$ & NS & $<0.0001$ \\
\hline CABG & $64(10 \%)$ & $21(9 \%)$ & $8(7 \%)$ & NS & NS & NS \\
\hline Cardiogenic shock & $5(0.8 \%)$ & $11(4.8 \%)$ & $3(2.6 \%)$ & 0.0004 & NS & NS \\
\hline Mortality at 2 years & $28(4 \%)$ & $16(7 \%)$ & $8(7 \%)$ & NS & NS & NS \\
\hline
\end{tabular}

$P C l$ - percutaneous coronary intervention, $C A B G$ - coronary artery bypass grafting.

Table IV. Significant independent risk factors for time to death from stepwise Cox regression analysis

\begin{tabular}{|lccccc|}
\hline Risk factors & $\begin{array}{c}\text { Parameter } \\
\text { estimate }\end{array}$ & Standard error & Hazard ratio & $\begin{array}{c}\text { 95\% confidence } \\
\text { intervals }\end{array}$ & $P$-value \\
\hline Age & 0.070 & 0.017 & 1.072 & $1.037-1.109$ & 0.0001 \\
\hline Body mass index & -0.069 & 0.025 & 0.933 & $0.888-0.980$ & 0.005 \\
\hline Serum creatinine & 0.404 & 0.075 & 1.498 & $1.294-1.733$ & $<0.0001$ \\
\hline Obstructed graft & 1.177 & 0.461 & 3.243 & $1.315-7.998$ & 0.011 \\
\hline
\end{tabular}

less likely to be treated with aspirin ( $86 \%$ vs. $94 \%$, $p=0.002)$, were less likely to be treated with clopidogrel $(29 \%$ vs. $56 \%, p<0.0001)$, were less likely to be treated with statins (75\% vs. $89 \%, p<0.0001)$, and had similar 2-year mortality (7\% vs. $4 \%$ ). A limitation of this study is that we do not have separate data for patients who had ST-segment elevation myocardial infarction, non-ST-segment elevation myocardial infarction, unstable angina pectoris, and stable angina pectoris.
Patients who had chest pain alone showed no significant differences in baseline characteristics, coronary angiographic findings, and 2-year mortality compared to patients who had both chest pain and dyspnea. The patients who had dyspnea alone were older (67 years vs. 64 years, $p=0.03)$, had higher serum creatinine $(1.3 \mathrm{mg} / \mathrm{dl}$ vs. $1.1 \mathrm{mg} / \mathrm{dl}, p=0.04)$, had a lower left ventricular ejection fraction ( $47 \%$ vs. $50 \%, p=0.04$ ), were less likely to be treated with aspirin ( $86 \%$ vs. $96 \%$, 
$p=0.02)$, were less likely to be treated with clopidogrel $(29 \%$ vs. $57 \%, p<0.0001)$, had less obstructive right CAD ( $28 \%$ vs. $40 \%, p=0.03)$, had more nonobstructive right CAD $(53 \%$ vs. $38 \%$, $p=0.02)$, had less percutaneous coronary intervention $(10 \%$ vs. $33 \%, p<0.0001)$, and had similar 2-year mortality (7\% vs. 7\%).

The log rank test showed no significant difference in time to death between the chest pain group and the dyspnea group. Significant independent risk factors for time to death from stepwise Cox regression analysis were age $(H R=1.072$, $p<0.0001)$, body mass index $(H R=0.933, p=0.005)$, serum creatinine $(H R=1.498, p=0.0001)$, and obstructed coronary artery bypass graft $(H R=3.243$, $p=0.011$ ). It was surprising that diabetes mellitus was not a significant independent risk factor for time to death. Our study may have been underpowered for mortality.

In conclusion, the data from the present study require independent confirmation. The present data show differences between patients undergoing coronary angiography because of chest pain versus dyspnea, with the chest pain group having more obstructive CAD, being more likely to have percutaneous coronary intervention, but having similar 2-year mortality.

\section{Conflict of interest}

The authors declare no conflict of interest.

\section{References}

1. Aronow WS, Fleg JL. Diagnosis of coronary heart disease in the elderly. In: Tresch and Aronow's Cardiovascular Disease in the Elderly. Aronow WS, Fleg JL, Rich MW (eds.). $5^{\text {th }}$ ed. Boca Raton, London, New York, CRC Press 2013; 191-214.

2. Aronow WS, Frishman WH. Angina pectoris in the elderly. In: Tresch and Aronow's Cardiovascular Disease in the Elderly. $5^{\text {th }}$ ed. Aronow WS, Fleg JL, Rich MW (eds.). Boca Raton, London, New York, CRC Press, 2013; 215-37.

3. Nakanishi R, Rana JS, Rozanski A, et al. Relationship of dyspnea vs. typical angina to coronary artery disease severity, burden, composition and location on coronary CT angiography. Atherosclerosis 2013; 230: 61-6.

4. Argulian E, Agarwal V, Bangalore S, et al. Meta-analysis of prognostic implications of dyspnea versus chest pain in patients referred for stress testing. Am J Cardiol 2014; 113: 559-64.

5. Hellenkamp K, Darius H, Giannitisis E, et al. The German CPU Registry: dyspnea independently predicts negative short-term outcome in patients admitted to German Chest Pain Units. Int J Cardiol 2014; 181C: 88-95.

6. Christopher Jones R, Pothier CE, Blackstone EH, Lauer MS. Prognostic importance of presenting symptoms in patients undergoing exercise testing for evaluation of known or suspected coronary disease. Am J Med 2004, 117: 380-9.

7. Chilappa K, Aronow WS, Rajdev A, et al. Mortality at long-term follow-up of patients with no, nonobstructive, and revascularized 1-, 2-, and 3-vessel obstructive coronary artery disease. Med Sci Monit 2010; 16: RA 120-3.

8. Veselka J. The time has come to move from coronary angiography to physiological assessment of coronary lesions. Arch Med Sci 2013; 9: 1-2.

9. Lai HM, Aronow WS, Mercando AD, et al. Risk factor reduction in progression of angiographic coronary artery disease. Arch Med Sci 2012; 8: 444-8. 